\title{
Pattern of Maternal Complications and Low Birth Weight: Associated Risk Factors among Highly Endogamous Women
}

\author{
Abdulbari Bener, ${ }^{1,2,3}$ Khalil M. K. Salameh, ${ }^{4}$ Mohammad T. Yousafzai, ${ }^{1,3}$ and Najah M. Saleh \\ ${ }^{1}$ Department of Epidemiology and Medical Statistices, Hamad General Hospital, Hamad Medical Corporation, Qatar \\ ${ }^{2}$ Department Evidence for Population Health Unit, School of Epidemiology and Health Sciences, \\ The University of Manchester, Manchester, UK \\ ${ }^{3}$ Departments of Public Health and Medical Education, Weill Cornell Medical College, P.O. Box 3050, Doha, Qatar \\ ${ }^{4}$ NICU Unit, Women's Hospital, Hamad Medical Corporation, Qatar \\ ${ }^{5}$ Obstetrics and Gynecology Department, Women's Hospital, Hamad Medical Corporation, Qatar
}

Correspondence should be addressed to Abdulbari Bener, abener@hmc.org.qa

Received 13 May 2012; Accepted 9 July 2012

Academic Editors: I. Diez-Itza, J. Olsen, and G. Rizzo

Copyright ( $\odot 2012$ Abdulbari Bener et al. This is an open access article distributed under the Creative Commons Attribution License, which permits unrestricted use, distribution, and reproduction in any medium, provided the original work is properly cited.

Objective. The objective of the study was to examine the pattern of low birth weight LBW, maternal complications, and its related factors among Arab women in Qatar. Design. This is a prospective hospital-based study. Setting. The study was carried out in Women's Hospital, Doha. Subjects and Methods. Pregnant women in their third trimester were identified in the log book of Women's Hospital and recruited into the study during first week of January 2010 to July 2011. Only 1674 (out of 2238) Arab women $(74.7 \%)$ consented to participate in this study. Data on clinical and biochemistry parameters were retrieved from medical records. Follow-up data on neonatal outcome was obtained from labor room register. Results. The incidence of LBW $(<2500 \mathrm{~g})$ was $6.7 \%$ among Arab women during 2010 in Qatar. Distribution of gestational diabetes mellitus (GDM), antepartum hemorrhage (APH), maternal anemia, premature rupture of membrane (PROM), maternal occupation, parity, sheesha smoking, and parental consanguinity were significantly different $(P<0.05)$ between mothers of LBW and normal birth weight NBW $(\geq 2500$ g) babies. Multivariable logistic regression analysis revealed that previous LBW, consanguinity, parity, smoking shesha, GDM, APH, anemia, PROM, maternal occupation, and housing condition were significantly associated with LBW adjusting for gestational age. Conclusion. Maternal complications such as GDM, APH, anemia, PROM, and smoking shesha during pregnancy are significantly increasing the risk of LBW outcome. Screening and prompt treatment for maternal complications and health education for smoking cessation during routine antenatal visits will help in substantial reduction of LBW outcome.

\section{Introduction}

Complications of pregnancy and child birth are the leading causes of disability and death among women of reproductive age in developing countries accounting for at least $18 \%$ of the global burden of disease in this age group [1]. Similarly, the pattern of leading causes of maternal death and disability is closely linked to poor maternal health during pregnancy, inadequate care during delivery, and lack of new born care [1]. Every year, almost 8 million still births and early neonatal deaths occur. In addition to maternal deaths, more than 50 million women experience maternal health problems annually [2]. In underdeveloped countries, those LBW and maternal complications often pose an immediate financial burden on women and their households.

With the advent of modern medicine, labour and delivery have become much safer for both mother and baby, but complications still occur. The third trimester, which is 28th week onwards till delivery, is like the last lap of the pregnancy journey. This period is a period where certain obstetric and medical problems can develop and a crucial phase for baby's weight gain. The adverse events that occur during pregnancy influence the health of the infant that may result in the neonatal outcome. The main potential complications that 
affect the mother during the third trimester are pregnancyinduced hypertension (preeclampsia and eclampsia), gestational diabetes, anaemia, bleeding, placenta praevia, abruptio placenta, vasa praevia, preterm labour, premature rupture of membrane, and so forth.

The health of a pregnant woman has a profound effect on the health of the developing fetus and new born [3]. According to World Health Organization, congenital malformations are now the 3rd leading cause of infant mortality, accounting for $12.7 \%$ of early neonatal mortality [4]. It was reported that $70-80 \%$ of all neonatal mortality and morbidity is due to preterm birth which is one of the major clinical problems in obstetrics and neonatology [5]. Infants born to women with diabetes are at increased risk for adverse birth outcomes $[6,7]$. More recently reported study on gestational diabetes is considered to be a major public health problem associated with higher perinatal mortality and morbidity rates $[6,7]$.

The objective of the study was to examine the pattern of low birth weight, maternal complications, and related factors that occur in the third trimester of Arab women.

\section{Subjects and Methods}

This is a prospective hospital-based study conducted among the Arab pregnant women in third trimester during January 2010 to July 2011. The study was based on the log book of the Women's Hospital which registers all the pregnant women visiting antenatal clinics of Women's Hospital, Hamad Medical Corporation. The research assistants screened the log book of Women's Hospital during the study period and prepared a list of 2,238 Arab pregnant women above 24 weeks of gestation with any maternal complication. All the eligible women on the prepared list $(N=2,238)$ were approached and consent was sought. Only 1674 women (74.7\%) consented to participate in the study (refer to Figure 1). In 2010, there were a total of 16,188 deliveries in the Women's Hospital. Our study sample included 1674 pregnant women which is $10.3 \%$ of the mothers delivered. The study was approved by the Hamad Medical Corporation prior to commencing data collection. Each participant was provided with brief information about the study and was assured of strict confidentiality.

Data was collected through face-to-face interview by qualified nurses using a validated questionnaire in the local language. The questionnaire covered sociodemographic characteristics of the pregnant women, family and medical history. The questionnaire was pilot-tested on 100 randomly selected pregnant women for the validity. The investigators made necessary corrections and modifications after considering the minor differences and discrepancies that had been found during the pilot study. Data on maternal complications of each patient were retrieved from the medical record file. In addition, follow-up data on pregnancy and neonatal outcome of each woman were obtained from the labour room register immediately after delivery (Figure 1).

The study was approved by the IRB of Research Ethics Committee of Hamad Medical Corporation (HMC-MRC)

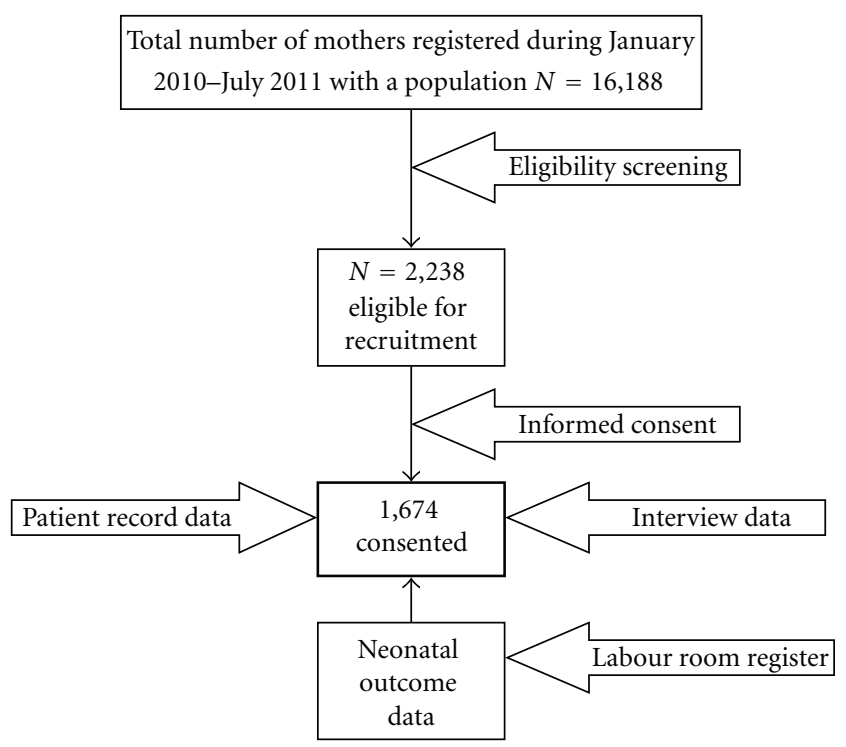

FIGURE 1: Flow diagram of representative sample studied $N=$ 1,674 .

and by the IRB of Weill Cornell Medical College (WCMCQ).

Data were analyzed using SPSS version 19. Student's $t$-test was used to ascertain the significance of differences between mean values of two continuous variables. Fisher Exact and Chi-Square tests were performed to test for differences in proportions of categorical variables between two or more groups. Univariate logistic regression analyses were carried out to identify possible predictors of LBW $(<2500 \mathrm{~g})$. Adjusted odds ratios for all variables that were significantly associated with LBW were computed using a multiple logistic regression model for controlling the simultaneous confounding effects of possible confounders. Hosmer-Lemeshow goodness-of-fit test was used to assess the model adequacy. All statistical tests were two-sided, and $P<0.05$ was considered statistically significant.

\section{Results}

The incidence of low birth weight $(<2500 \mathrm{~g})$ was $6.7 \%$ during the period 2010 in Qatar. Table 1 shows distribution of sociodemographic characteristics across LBW and NBW babies. There was no statistical difference between LBW and NBW in terms of nationality, maternal age, maternal education, household monthly income, place of living, and father's occupation. However, mother's occupation (house wife or working) and type of residence (villa, apartment, or population house) were significantly different $(P-0.009$ and 0.033 , resp.) between LBW and NBW babies. Almost three quarters of the LBW babies were born to mothers who were housewives as compare to almost a quarter of LBW babies to mothers working outside.

Table 2 shows distribution of maternal and obstetric characteristics across LBW and NBW babies. There was a significant difference between mothers with LBW and NBW 
TABLE 1: Sociodemographic characteristics among mothers of LBW and NBW babies in Qatar $(N=1674)$.

\begin{tabular}{|c|c|c|c|}
\hline Variable & LBW $n=112(\%)$ & NBW $n=1562(\%)$ & $P$ value* \\
\hline \multicolumn{4}{|l|}{ Nationality } \\
\hline Qatari & $56(50.0)$ & $728(46.6)$ & \multirow{2}{*}{0.487} \\
\hline Non-Qatari & $56(50.0)$ & $834(53.4)$ & \\
\hline \multicolumn{4}{|l|}{ Maternal age at delivery } \\
\hline$<25$ yrs & $20(17.9)$ & $246(15.7)$ & \multirow{3}{*}{0.743} \\
\hline $25-34$ yrs & $56(50.0)$ & $766(49.0)$ & \\
\hline$\geq 35$ yrs & $36(32.1)$ & $550(35.2)$ & \\
\hline \multicolumn{4}{|l|}{ Maternal education } \\
\hline Primary or below & $28(25.0)$ & $267(17.1)$ & \multirow{3}{*}{0.120} \\
\hline Intermediate & $10(8.9)$ & $139(8.9)$ & \\
\hline Secondary and above & $74(66.1)$ & $1156(74.0)$ & \\
\hline \multicolumn{4}{|l|}{ Mother's occupation } \\
\hline House wife & $81(72.3)$ & 935 (59.9) & \multirow{2}{*}{0.009} \\
\hline Working outside & $31(27.7)$ & $627(40.1)$ & \\
\hline \multicolumn{4}{|l|}{ Household income $\left(\int\right)$} \\
\hline$<10,000$ & $56(50.0)$ & $731(46.8)$ & \multirow{2}{*}{0.512} \\
\hline$\geq 10,000$ & $56(50.0)$ & $831(53.2)$ & \\
\hline \multicolumn{4}{|l|}{ Type of residence } \\
\hline Villa & $67(59.8)$ & $1027(65.7)$ & \multirow{3}{*}{0.033} \\
\hline Apartment & $5(4.5)$ & $135(8.6)$ & \\
\hline Popular house & $40(35.7)$ & $1027(65.7)$ & \\
\hline \multicolumn{4}{|l|}{ Place of living } \\
\hline Urban & $94(83.9)$ & $1334(85.4)$ & \multirow{2}{*}{0.670} \\
\hline Semi urban & $18(16.1)$ & $228(14.6)$ & \\
\hline \multicolumn{4}{|l|}{ Father's occupation } \\
\hline Business & $21(18.8)$ & $263(16.8)$ & \multirow{4}{*}{0.263} \\
\hline Retired & $20(17.9)$ & $230(14.7)$ & \\
\hline Professional & $11(9.8)$ & $260(16.6)$ & \\
\hline Others & $60(53.6)$ & 809 (51.8) & \\
\hline
\end{tabular}

f: Qatari Riyal, LBW: low birth weight (birth weight less than $2500 \mathrm{~g}$ ), NBW: normal birth weight (2500 g or more).

* Two-sided $P$ values based on Chi-Square test.

babies in terms of consanguinity $(P=0.021)$, parity $(P-$ $0.038)$, previous LBW $(P=0.006)$, and shesha smoking $(P=0.024)$. No significant difference was observed in terms of maternal BMI, previous LBW, previous abortion, and antenatal care.

Table 3 shows distribution of maternal complications across LBW and NBW babies. There was a significant difference in terms of GDM $(P-0.032)$, APH $(P-0.046)$, anemia $(P-0.050)$, PROM $(P-0.007)$, and gestational age groups $(<0.001)$.

Table 4 shows determinants of LBW based on multivariable logistic regression analysis. Previous LBW (Adj. OR 1.9; 95\% CI 1.3-3.1), consanguinity (Adj. OR 1.6; 95\% CI 1.12.3 ), parity (2-3 versus $<2$, Adj. OR $1.8 ; 95 \%$ CI $1.1-3.1$ and $\geq 4$ versus $<2$, Adj. OR 2.0; 95\% CI 1.2-3.3), smoking shesha (Adj. OR 2.0; 95\% CI 1.1-3.7), GDM (Adj. OR 1.8; 95\% CI 1.1-3.4), APH (Adj. OR 1.6; 95\% CI 1.1-2.5), anemia (Adj. OR 1.6; 95\% CI 1.0-2.4), PROM (Adj. OR 2.3; 95\% CI 1.2-4.2), maternal occupation (working versus house wife, adjusted OR 0.6; 95\% CI 0.4-0.9), and housing condition (apartment versus villa, Adj. OR 0.6; 95\% CI 0.2-1.4 and popular house versus villa, Adj. OR 1.5; 95\% CI 1.1-2.3) were significantly associated with LBW adjusting for gestational age.

\section{Discussion}

The present study highlighted the potential maternal complications that affected the mother during the third trimester and its effect on neonatal birth weight among Arab women in Qatar. It is important to identify the risk factors early in the prenatal period so that appropriate interventions are established to ensure the well-being of the mother and child. In the study sample, majority of the pregnant women with low monthly household income experienced more complications during pregnancy $(38.2 \%)$ with a higher frequency among expatriate Arab women (41.7\%) than Qatari women $(33.8 \%)$. Most of them were housewives $(60.8 \%)$ and with university degree $(42 \%)$. Also, advancing 
TABLE 2: Maternal and obstetric characteristics among mothers of LBW and NBW babies in Qatar $(N=1674)$.

\begin{tabular}{|c|c|c|c|}
\hline Variable & LBW $n=112(\%)$ & NBW $n=1562(\%)$ & $P$ value \\
\hline \multicolumn{4}{|c|}{ Body mass index $\left(\mathrm{Kg} / \mathrm{m}^{2}\right)$} \\
\hline Normal & $46(41.1)$ & $779(49.9)$ & \multirow{3}{*}{0.136} \\
\hline Overweight & $32(28.6)$ & $420(26.9)$ & \\
\hline Obese & $34(30.3)$ & $323(23.2)$ & \\
\hline \multicolumn{4}{|c|}{ Consanguinity in parents } \\
\hline Yes & $45(40.2)$ & $536(34.3)$ & \multirow{2}{*}{0.021} \\
\hline No & $67(59.8)$ & $1026(65.7)$ & \\
\hline \multicolumn{4}{|l|}{ Parity } \\
\hline$<2$ & $19(17.0)$ & $434(27.8)$ & \multirow{4}{*}{0.038} \\
\hline $2-3$ & $32(28.6)$ & $417(26.7)$ & \\
\hline $4-6$ & $57(50.9)$ & $625(40.0)$ & \\
\hline$>6$ & $4(3.6)$ & $86(5.5)$ & \\
\hline \multicolumn{4}{|l|}{ Previous LBW } \\
\hline Yes & $21(18.8)$ & $158(10.1)$ & \multirow{2}{*}{0.006} \\
\hline No & $91(81.3)$ & $1404(89.9)$ & \\
\hline \multicolumn{4}{|c|}{ Previous abortion } \\
\hline Yes & $20(17.9)$ & $207(13.3)$ & \multirow{2}{*}{0.134} \\
\hline No & $92(82.1)$ & $1355(81.7)$ & \\
\hline \multicolumn{4}{|c|}{ Previous still birth } \\
\hline Yes & $12(10.7)$ & $132(8.5)$ & \multirow{2}{*}{0.409} \\
\hline No & $100(89.3)$ & $1430(91.5)$ & \\
\hline \multicolumn{4}{|l|}{ Antenatal care } \\
\hline Yes & $90(80.4)$ & $1210(77.5)$ & \multirow{2}{*}{0.478} \\
\hline No & $22(19.6)$ & $352(22.5)$ & \\
\hline \multicolumn{4}{|l|}{ Shesha smoking } \\
\hline Yes & 13 (11.6) & $96(6.1)$ & \multirow{2}{*}{0.024} \\
\hline No & $99(88.4)$ & 1466 (93.9) & \\
\hline
\end{tabular}

LBW: low birth weight (birth weight less than $2500 \mathrm{~g}$ ), NBW: normal birth weight (2500 g or more).

* Two-sided $P$ values based on Chi-Square test.

maternal age especially aged 35 years or older has been accepted to have more risks from both the maternal and fetal perspectives.

The study findings revealed that the obstetrical complications as well as neonatal morbidity were higher among older women above 35 years. Previous studies suggested that women aged over 35 years are at increased risk for obstetrical complications as well as perinatal morbidity and mortality $[8,9]$. The leading maternal complications were significantly higher among women aged 35 years and above compared to younger women below 35 years; mainly gestational diabetes (20.8\% versus $13.4 \% ; P<0.001)$, gestational hypertension (21.6\% versus $15.2 \% ; P=0.003)$, and antepartum haemorrhage $(17.9 \%$ versus $13.7 \% ; P=0.042)$. The modern infertility treatment has increased the number of women able to become pregnant at advanced age. The outcome of these pregnancies raised significant concern because older age is associated inherently with higher incidence of chronic diseases. Another study by Üstün et al. [10] found similar results that complications of pregnancy were higher in the older group.

Harrison [11] stated in their study that one quarter of all adult women living in the developed world currently suffer from a short- or long-term illness related to pregnancy and childbirth. Roberts and Cooper [12] reported that gestational hypertension and severe preeclampsia are leading causes of maternal and fetal/neonatal morbidity and mortality which is similar to our study results. Maternal anemia is considered as a risk factor for adverse pregnancy outcome [13]. Estimates from the World Health Organization report [14] that $35 \%$ to $75 \%$ of pregnant women in developing countries and $18 \%$ of women from industrialized countries are anemic. Low birth weight in anemic women has been observed in the present study $(24.1 \%)$. There is substantial amount of evidence showing that maternal anemia in pregnancy can result in low birth weight subsequent to preterm delivery [15].

It was documented that the prevalence of gestational diabetes is increasing all over the world $[6,16-18]$ and the risks include an increased risk of macrosomia, birth injuries, and caesarean deliveries $[6,16,18]$. Our rate of macrosomia $(42.3 \%)$ is strikingly similar to a prospective study in The Netherlands [19]. In Saudi Arabia [20], it was found that congenital malformations and neonatal jaundice were the most common problems among babies of gestational diabetic mothers. 
TABLE 3: Maternal complications among mothers of LBW and NBW babies in Qatar $(N=1674)$.

\begin{tabular}{|c|c|c|c|}
\hline Variable & LBW $n=112(\%)$ & NBW $n=1562(\%)$ & $P$ value* \\
\hline \multicolumn{4}{|c|}{ Gestational diabetes mellitus } \\
\hline Yes & $13(11.6)$ & $311(19.9)$ & \multirow{2}{*}{0.032} \\
\hline No & $99(88.4)$ & $1251(80.1)$ & \\
\hline \multicolumn{4}{|c|}{ Pregnancy hypertension } \\
\hline Yes & $15(13.4)$ & $289(18.5)$ & \multirow{2}{*}{0.175} \\
\hline No & $97(86.8)$ & $1273(81.5)$ & \\
\hline \multicolumn{4}{|c|}{ Antepartum hemorrhage } \\
\hline Yes & $24(21.4)$ & $226(14.5)$ & \multirow{2}{*}{0.046} \\
\hline No & $88(78.6)$ & $1336(85.5)$ & \\
\hline \multicolumn{4}{|l|}{ Anemia } \\
\hline Yes & $27(24.1)$ & $265(17.0)$ & \multirow{2}{*}{0.050} \\
\hline No & $85(75.9)$ & $1297(83.0)$ & \\
\hline \multicolumn{4}{|c|}{ Premature rupture of membrane } \\
\hline Yes & $13(11.6)$ & $85(5.4)$ & \multirow{2}{*}{0.007} \\
\hline No & $99(88.4)$ & $1477(94.6)$ & \\
\hline \multicolumn{4}{|c|}{ Gestational age (weeks) } \\
\hline $28-31$ & $7(6.3)$ & $9(0.6)$ & \multirow{3}{*}{$<0.001$} \\
\hline $31-36$ & $12(10.7)$ & $31(2.0)$ & \\
\hline$\geq 36$ & $93(83.0)$ & $1522(97.4)$ & \\
\hline \multicolumn{4}{|c|}{ Preterm delivery } \\
\hline Yes & $23(20.5)$ & $155(9.9)$ & \multirow{2}{*}{$<0.001$} \\
\hline No & $89(79.5)$ & $1407(90.1)$ & \\
\hline
\end{tabular}

LBW: low birth weight (birth weight less than $2500 \mathrm{~g}$ ), NBW: normal birth weight ( $2500 \mathrm{~g}$ or more).

* Two-sided $P$ values based on Chi-Square test.

The current study has shown that maternal complications are major contributors to neonatal complications. A high-risk pregnancy with maternal complications was observed among women of advanced age. Women with severe maternal complications like gestational hypertension, maternal anaemia, gestational diabetes, antepartum haemorrhage had a greater chance to have a poor neonatal outcome. Gestational diabetes increased the risk of macrosomia and caesarean delivery. The high consanguinity rate, advanced maternal age, and past obstetric risk of congenital anomalies in studied women might have increased the risk of congenital anomalies in newborns of older women. Low birth weight was found higher in maternal anaemia and antepartum haemorrhage.

In last, the study highlighted the association of maternal complications, lack of family planning practices (parity > 2 ), and maternal shesha smoking with delivering low birth weight babies. Early identification and prompt treatment for maternal complications and health education for smoking cessation during routine antenatal visits will help in substantial reduction of LBW outcome. Mass awareness should be created by utilizing mass and print media regarding early signs of maternal complications, smoking cessation, and essential family planning practices to promote primary prevention of LBW in Qatar.

\section{Conflict of Interests}

All authors declare that they have no conflict of interests. The sponsor of the study had no role in study design; in the collection, analysis, and interpretation of data; in the writing of this report; in the decision to submit the paper for publication.

\section{Authors' Contribution}

A. Bener designed and supervised the study and was involved in data collection, statistical analysis, and the writing of the paper. The coauthors N. M. Saleh, M. T. Yousafzai, and K. M. K. Salameh were involved in data collection, and interpretation of data. All authors approved the final version.

\section{Acknowledgment}

The project was supported and funded by the Qatar Foundation, Qatar National Research Fund Grant no. UREP-08-0903-018. The authors also would like to thank Hamad Medical Corporation (HMC Research Protocol no. 10146/10) and the Weill Cornell Medical College-Qatar Institutional Review Board (IRB no. 2010-0021) for their ethical approval of this study. 
TABLE 4: Determinants of low birth weight among newborn babies in Qatar $(N=1674)$.

\begin{tabular}{|c|c|c|}
\hline & Adj. OR (95\% CI) & $P$ value* \\
\hline \multicolumn{3}{|l|}{ Previous LBW } \\
\hline No & 1 & \multirow{2}{*}{0.006} \\
\hline Yes & $1.9(1.3-3.1)$ & \\
\hline \multicolumn{3}{|l|}{ Consanguinity } \\
\hline No & 1 & \multirow{2}{*}{0.021} \\
\hline Yes & $1.6(1.1-2.3)$ & \\
\hline \multicolumn{3}{|l|}{ Parity } \\
\hline$<2$ & 1 & \multirow{3}{*}{0.043} \\
\hline $2-3$ & $1.8(1.1-3.1)$ & \\
\hline$\geq 4$ & $2.0(1.2-3.3)$ & \\
\hline \multicolumn{3}{|l|}{ Smoking shesha } \\
\hline No & 1 & \multirow{2}{*}{0.026} \\
\hline Yes & $2.0(1.1-3.7)$ & \\
\hline \multicolumn{3}{|c|}{ Gestational diabetes mellitus } \\
\hline No & 1 & \multirow{2}{*}{0.034} \\
\hline Yes & $1.8(1.1-3.4)$ & \\
\hline \multicolumn{3}{|c|}{ Antepartum hemorrhage } \\
\hline No & 1 & \multirow{2}{*}{0.048} \\
\hline Yes & $1.6(1.1-2.5)$ & \\
\hline \multicolumn{3}{|l|}{ Anemia } \\
\hline No & 1 & \multirow{2}{*}{0.050} \\
\hline Yes & $1.6(1.0-2.4)$ & \\
\hline \multicolumn{3}{|c|}{ Premature rupture of membrane } \\
\hline No & 1 & \multirow{2}{*}{0.009} \\
\hline Yes & $2.3(1.2-4.2)$ & \\
\hline \multicolumn{3}{|l|}{ Gestational age } \\
\hline $28-31$ & $12.7(4.6-34.9)$ & \multirow{3}{*}{$<0.001$} \\
\hline $31-35$ & $6.3(3.1-12.7)$ & \\
\hline$\geq 36$ & 1 & \\
\hline \multicolumn{3}{|l|}{ Maternal occupation } \\
\hline Housewife & 1 & \multirow{2}{*}{0.010} \\
\hline Working outside & $0.6(0.4-0.9)$ & \\
\hline \multicolumn{3}{|l|}{ Housing condition } \\
\hline Villa & 1 & \multirow{3}{*}{0.045} \\
\hline Apartment & $0.6(0.2-1.4)$ & \\
\hline Popular house & $1.5(1.1-2.3)$ & \\
\hline
\end{tabular}

Outcome $=$ birth weight $(1=$ low birth weight, $0=$ normal birth weight $)$.

* Two-sided $P$ values based on $-2 \log$ likelihood ratio statistics.

\section{References}

[1] Q. Ndiweni and E. J. Buchmann, "Unbooked mothers and their babies-what causes the poor outcomes?" South African Medical Journal, vol. 88, no. 2, pp. 192-199, 1998.

[2] K. A. Harrison, "Maternal mortality—a sharper focus on a major issue of our time," Tropical Journal of Obstetrics and Gynaecology, vol. 1, no. 1, pp. 9-13, 1988.

[3] A. M. Beggs, G. Bucks, M. Gorwin et al., "Targetting Sudden Infant Death Syndrome (SIDS): A Strategic Plan,” 2001, http://www.nichd.nih.gov/publicatins/pubs/upload?SIDS_syndrome.pdf.
[4] N. T. N. Ngoc, M. Merialdi, H. Abdel-Aleem et al., "Causes of stillbirths and early neonatal deaths: data from 7993 pregnancies in six developing countries," Bulletin of the World Health Organization, vol. 84, no. 9, pp. 699-705, 2006.

[5] R. L. Goldenberg, "The management of preterm labour, High risk pregnancy series: an expert view," Obstetrics \& Gynecology, vol. 100, no. 5, pp. 1020-1034, 2002.

[6] A. Bener, N. M. Saleh, and A. Al-Hamaq, "Prevalence of gestational diabetes and associated maternal and neonatal complications in a fast-developing community: global comparisons," International Journal of Women's Health, vol. 3, no. 1, pp. 367-373, 2011.

[7] W. J. Meyer, J. Carbone, D. W. Gauthier, and D. A. Gottmann, "Early gestational glucose screening and gestational diabetes," Journal of Reproductive Medicine for the Obstetrician and Gynecologist, vol. 41, no. 9, pp. 675-679, 1996.

[8] F. G. Cunningham and K. J. Leveno, "Childbearing among older women - the message is cautiously optimistic," The New England Journal of Medicine, vol. 333, no. 15, pp. 1002-1003, 1995.

[9] I. M. Itil, A. A. Ozsaran, M. Kazandi, M. C. Tereck, and N. Askar, "Evaluation of pregnancies of women aged 40 and older," Journal of Obstetrics and Gynaecology, vol. 10, pp. 21$24,2000$.

[10] Y. Üstün, Y. Engin-Üstün, M. Meydanli, R. Atmaca, and A. Kafkasli, "Maternal and neonatal outcomes in pregnancies at 35 and older age group," Journal of the Turkish German Gynecology Association, vol. 6, no. 1, pp. 46-48, 2005.

[11] K. A. Harrison, "Maternal mortality-a sharper focus on a major issue of our time," Tropical Journal of Obstetrics and Gynaecology, vol. 1, no. 1, pp. 9-13, 1988.

[12] J. M. Roberts and D. W. Cooper, "Pathogenesis and genetics of pre-eclampsia," The Lancet, vol. 357, no. 9249, pp. 53-56, 2001.

[13] G. Pappas, T. Akhtar, P. J. Gergen, W. C. Hadden, and A. Q. Khan, "Health status of the Pakistani population: a health profile and comparison with the United States," American Journal of Public Health, vol. 91, no. 1, pp. 93-98, 2001.

[14] World Health Organization, The Prevalence of Anemia in Women: A Tabulation of Available Information, WHO, Geneva, Switzerland, 2nd edition, 1992.

[15] R. L. Goldenberg, T. Tamura, M. DuBard, K. E. Johnston, R. L. Copper, and Y. Neggers, "Plasma ferritin and pregnancy outcome," American Journal of Obstetrics and Gynecology, vol. 175, no. 5, pp. 1356-1359, 1996.

[16] D. Dabelea, J. K. Snell-Bergeon, C. L. Hartsfield, K. J. Bischoff, R. F. Hamman, and R. S. McDuffie, "Increasing prevalence of gestational diabetes mellitus (GDM) over time and by birth cohort: Kaiser Permanente of Colorado GDM screening program," Diabetes Care, vol. 28, no. 3, pp. 579-584, 2005.

[17] A. Bener, M. Zirie, M. Musallam, Y. S. Khader, and A. O. A. A. Al-Hamaq, "Prevalence of metabolic syndrome according to adult treatment panel III and international diabetes federation criteria: a population-based study," Metabolic Syndrome and Related Disorders, vol. 7, no. 3, pp. 221-230, 2009.

[18] S. Rahman, K. Salameh, H. Al-Rifai et al., "Gestational age specific neonatal survival in the state of Qatar (2003-2008) —a comparative study with international benchmarks," Journal of the College of Physicians and Surgeons Pakistan, vol. 21, no. 9, pp. 542-547, 2011.

[19] R. C. Temple, V. J. Aldridge, and H. R. Murphy, "Prepregnancy care and pregnancy outcomes in women with type 1 diabetes," Diabetes Care, vol. 29, no. 8, pp. 1744-1749, 2006. 
[20] A. A. Sobande, M. Eskander, and E. I. Archibong, "Complications of pregnancy and foetal outcomes in pregnant diabetic patients managed in a tertiary hospital in Saudi Arabia," West African Journal of Medicine, vol. 24, no. 1, pp. 13-17, 2005. 


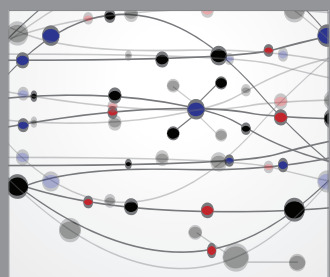

The Scientific World Journal
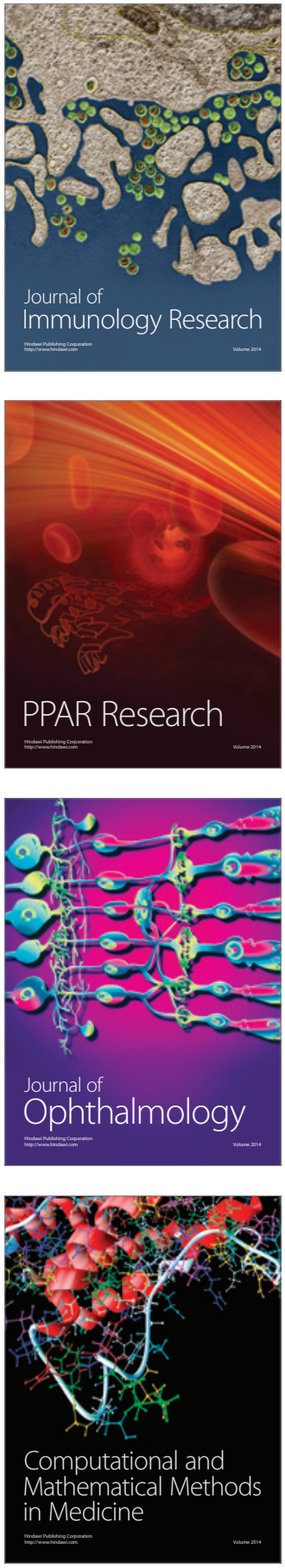

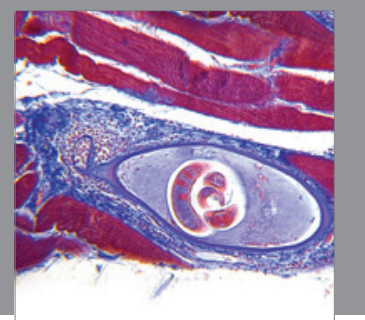

Gastroenterology

Research and Practice
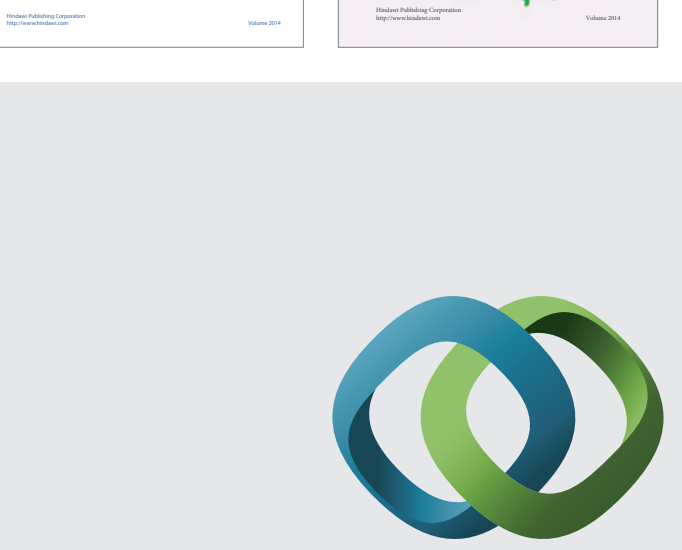

\section{Hindawi}

Submit your manuscripts at

http://www.hindawi.com
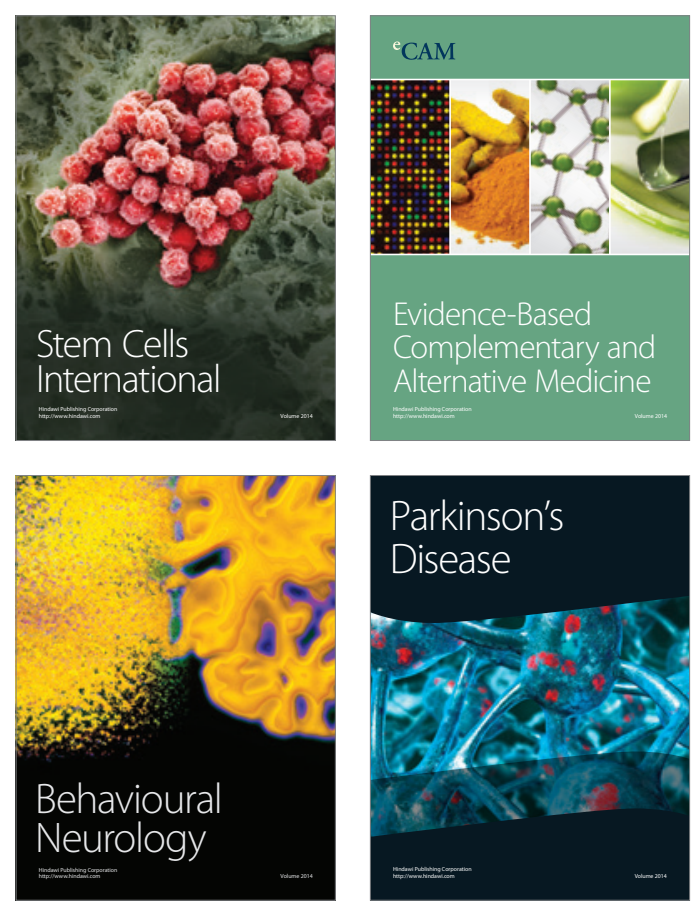

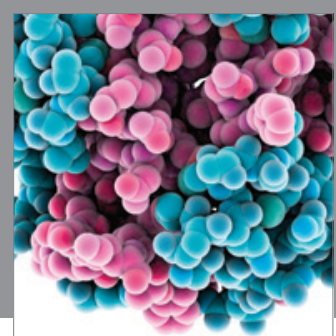

Journal of
Diabetes Research

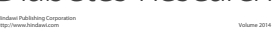

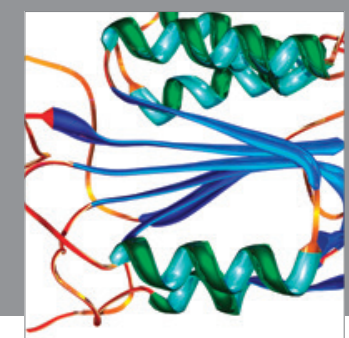

Disease Markers
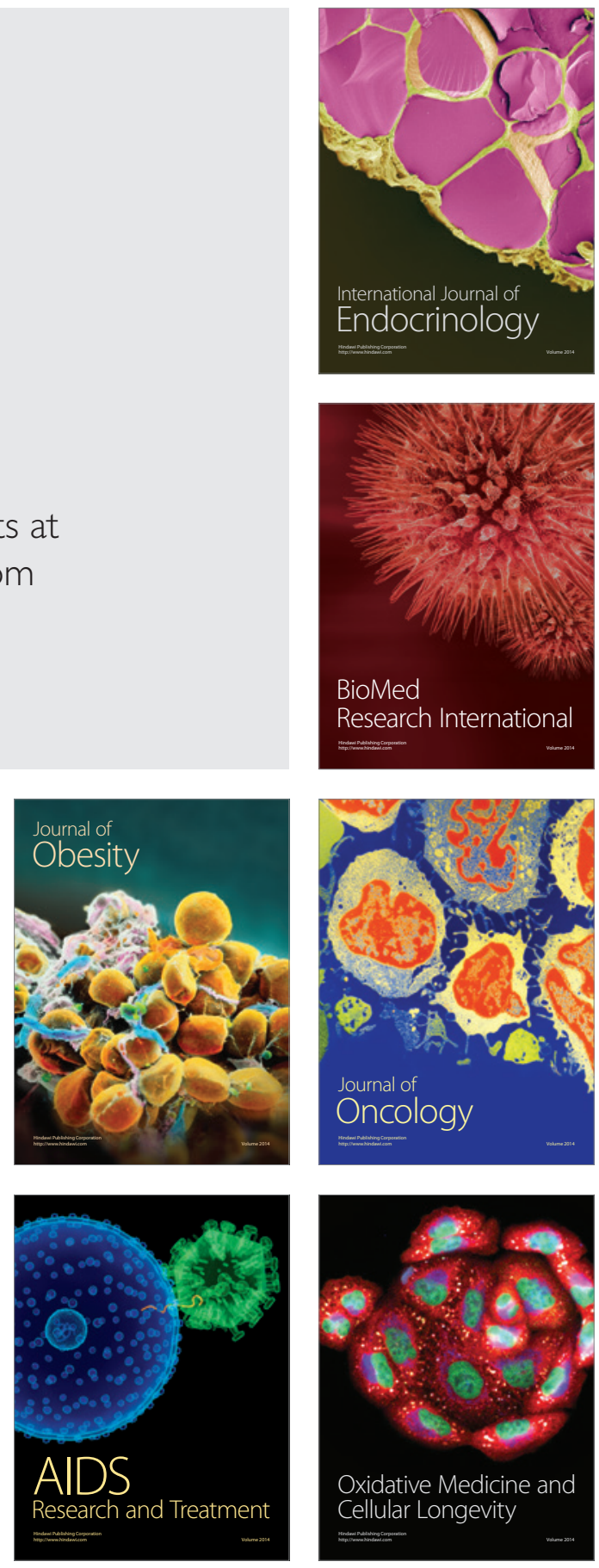